\title{
Boardroom ethics and the syndrome of senior silence
}

\author{
John J Turner consultant physician and honorary lecturer \\ University Hospital Aintree and Liverpool School of Medicine, Liverpool L9 7AL, UK
}

Whistleblowing is self evident failure, driven by the collapse of healthier communications, a product of an NHS climate disappointingly suspicious of open rigorous clinical debate. ${ }^{1}$ This climate is part of an insecure self protective management culture that represses alternative opinion. ${ }^{2}$ The phenomenon of senior silence, so puzzling to the wider public, is a deeply embedded syndrome, extending well beyond the slide into crisis exposed at the Mid Staffordshire Trust. ${ }^{3}$

For senior clinicians to rediscover their influence on operational policy, as the government insists it would like, urgent reform is needed to improve the ethical and functional integrity of many trust boards. ${ }^{4}$ The crucial medical director role, with its enhanced statutory powers, has moved from the boardroom advocate of balanced clinical opinion to the enforcer of policy, right or wrong.

Sanctions invoked to secure senior silence involve "reorganising" to remove less than sycophantic clinical leadership, blocking performance related remuneration, and resorting to the use or abuse of consultant suspension procedures.

The contrast with senior managers is stark and startling - they are not subject to independent regulation, their code of conduct is feeble, and there are no disciplinary powers comparable to the enhanced General Medical Council. Trust executives who are removed or resign enjoy reappointment elsewhere in the NHS, leavened by excessive compensation packages and concealed by the silence of the confidential non-disclosure (gagging) agreements routinely incorporated into employment contracts. $^{5}$

Competing interests: JJT is a Royal College of Physicians of London nominee and has provided independent case reviews for the Mid Staffordshire inquiry.

1 Godlee F. A change of culture, but how [Editor's Choice]? BMJ 2013;346:f1152. (20 February.)

2 Holmes D. Mid-Staffordshire scandal highlights NHS cultural crisis. Lancet 2013:381:9866.

3 Francis R. The Mid Staffordshire NHS Foundation Trust Public Inquiry. Final report. 2013. www.midstaffspublicinquiry.com/report.

4 Jarman B. When managers rule. BMJ 2012;345:e8239.

5 Hosken A. NHS chief stopped from speaking on patient safety. BBC News 2013 Feb 14. www.bbc.co.uk/mobile/health/news/story21444058.shtml.

Cite this as: BMJ 2013;346:f1358

๑ BMJ Publishing Group Ltd 2013 